\title{
Single-Inhaler Triple Therapy and Health-Related Quality of Life in COPD: The IMPACT Study
}

\author{
Maggie Tabberer - C. Elaine Jones · Sally Kilbride - David M. G. Halpin • \\ David A. Lomas · Steven Pascoe - Dave Singh - Robert A. Wise • \\ Gerard J. Criner · Peter Lange · Mark T. Dransfield · MeiLan K. Han • \\ Fernando J. Martinez · Morrys C. Kaisermann · David A. Lipson
}

Received: February 12, 2020 / Published online: July 9, 2020

(C) The Author(s) 2020

\section{ABSTRACT}

Introduction: The phase 3 InforMing the PAthway of COPD (chronic obstructive pulmonary disease) Treatment (IMPACT) trial, single-inhaler therapy with fluticasone furoate

Digital Features To view digital features for this article go to https://doi.org/10.6084/m9.figshare.12436334.

M. Tabberer $(\varangle) \cdot$ S. Kilbride

GlaxoSmithKline plc, Stockley Park West, Uxbridge, Middlesex, UK

e-mail: margaret.x.tabberer@gsk.com

C. E. Jones

GlaxoSmithKline plc, Research Triangle Park, NC, USA

D. M. G. Halpin

University of Exeter Medical School, College of

Medicine and Health, University of Exeter, Exeter, UK

D. A. Lomas

UCL Respiratory, University College London, London, UK

S. Pascoe - M. C. Kaisermann - D. A. Lipson GlaxoSmithKline plc, Collegeville, PA, USA

D. Singh

The Centre for Respiratory Medicine and Allergy, Institute of Inflammation and Repair, Manchester Academic Health Science Centre, University of Manchester, Manchester University NHS

Foundation Trust, Manchester, UK
(FF) $100 \mu \mathrm{g}$, umeclidinium (UMEC) $62.5 \mu \mathrm{g}$, and vilanterol (VI) $25 \mu$ g demonstrated a reduction in the rate of moderate or severe exacerbations compared with FF/VI or UMEC/VI in patients with symptomatic COPD at risk of exacerbations. This article reports additional evidence of improvements in symptoms and health-related quality of life (HRQoL) with FF/UMEC/VI compared with either FF/VI or UMEC/VI from the IMPACT study.

\section{R. A. Wise}

The Division of Pulmonary and Critical Care Medicine, Johns Hopkins University School of Medicine, Baltimore, MD, USA

\section{G. J. Criner}

Lewis Katz School of Medicine at Temple University, Philadelphia, PA, USA

\section{P. Lange}

University of Copenhagen, Copenhagen, Denmark

\section{T. Dransfield}

The Division of Pulmonary, Allergy, and Critical Care Medicine, Lung Health Center, University of Alabama at Birmingham, Birmingham, AL, USA

\section{K. Han}

University of Michigan, Pulmonary and Critical Care, Ann Arbor, MI, USA

\section{F. J. Martinez}

New York-Presbyterian Hospital/Weill Cornell Medical Center, New York, NY, USA

D. A. Lipson

Perelman School of Medicine, University of Pennsylvania, Philadelphia, PA, USA 
Methods: Patient-reported HRQoL assessments and symptom measures included as pre-specified IMPACT end points were the St George's Respiratory Questionnaire (SGRQ), COPD Assessment Test (CAT), and Baseline Dyspnea Index (BDI) as the anchor for the Transitional Dyspnea Index (TDI) focal score (BDI/TDI) in a subset of patients enrolled at study sites in North America and Europe. Change from baseline was assessed at weeks 4, 28, and 52 .

Results: The intent-to-treat population included 10,355 patients (TDI population: 5058 patients). Clinically meaningful improvements in SGRQ total score between baseline and week 52 favored FF/UMEC/VI over FF/VI ( -1.8 units, $p<0.001)$ and UMEC/VI $(-1.8$ units, $p<0.001)$. Similar improvements in the CAT and TDI focal score were also observed with FF/ UMEC/VI versus FF/VI or UMEC/VI.

Conclusions: This study demonstrates that in patients with symptomatic COPD at risk of exacerbations, once-daily FF/UMEC/VI, compared with FF/VI or UMEC/VI, improves patient-perceived HRQoL and symptoms.

Trial Registration Number: NCT02164513.

Keywords: COPD; Exacerbations; Healthrelated quality of life; IMPACT trial; Patientreported outcomes; Single-inhaler triple therapy

\section{Key Summary Points}

Why carry out this study?

Historically, improvements in lung function and exacerbation reduction have been the focus of trials to assess new treatments for COPD

However, the need to assess the impact of COPD symptoms on patient healthrelated quality of life is also important

This article provides additional evidence of improvements in patient-reported outcomes within the InforMing the PAthway of COPD Treatment (IMPACT; NCT02164513) study in patients with symptomatic COPD and a history of exacerbations

\section{What was learned from the study?}

Clinically meaningful improvements in patient-reported outcomes favored $\mathrm{FF} /$ UMEC/VI over FF/VI or UMEC/VI for the treatment of patients with symptomatic COPD at risk of exacerbations

Treatment of patients with symptomatic COPD at risk of exacerbations with FF/ UMEC/VI improves patient-perceived health-related quality of life and symptoms compared with FF/VI or UMEC/VI

\section{INTRODUCTION}

Historically, the focus of developing treatments for chronic obstructive pulmonary disease (COPD) has been targeted toward improvements in lung function and reductions in acute exacerbations [1-3]. More recently, however, the importance of assessing the impact of symptoms and physical impairment has been highlighted $[4,5]$. These factors have been shown to both substantially reduce patients' quality of life and increase healthcare resource utilization [4, 5]. Patient-reported outcome (PRO) measures are of increasing importance and have been applied in clinical studies to demonstrate patient-perceived changes in symptoms and health-related quality of life (HRQoL) [6].

Measuring the patients' perspective of treatment using patient-centered outcomes is therefore an important focus when assessing the benefits of novel therapies. Inclusion of reliable and responsive tools to assess symptoms and HRQoL provides complementary information to data about lung function and exacerbations, giving a broader view of the response to treatment and guiding clinical practice. Historically, response to treatment has been defined, at least in part, by comparing mean changes in the measure from baseline in relation to what was considered the minimum relevant effect that could be discerned by a patient. More recently, there has been greater interest in 
determining the proportion of patients who achieve a meaningful change with different therapies and a focus on defining this meaningful change $[7,8]$. The use of anchor-based approaches, whereby simple global questions are used as an external indicator against which changes can be determined, can allow crosssectional and longitudinal assessment of meaningful change [9]. Global anchor questions relating to disease severity or perceived change in disease severity can be used in studies alongside more complex measures of symptoms and HRQoL to define different levels of meaningful response for both improvement and deterioration of disease.

Previously published data $[1,6]$ demonstrated improvements in COPD symptoms and HRQoL during treatment with once-daily fluticasone furoate (FF), umeclidinium (UMEC), and vilanterol (VI) compared with the twice-daily inhaled corticosteroid/long-acting $\beta_{2}$-agonist (ICS/LABA) combination, budesonide/formoterol. This article provides additional evidence of an improvement in PROs with $\mathrm{FF} /$ UMEC/VI compared with either FF/VI or UMEC/VI by describing pre-specified symptom and HRQoL results from the InforMing the PAthway of COPD Treatment (IMPACT; NCT02164513) study in patients with symptomatic COPD and a history of exacerbations $[2,10]$.

\section{METHODS}

\section{Study Design}

The IMPACT study was a phase 3 landmark trial whose protocol $[2,10]$ and principal findings $[2,10]$ have been previously published. IMPACT was conducted in accordance with Good Clinical Practice guidelines and the provisions of the Declaration of Helsinki and received approval from local institutional review boards or independent ethics committees. The primary objective was to compare the effects of 52 weeks of a once-daily, single-inhaler combination of FF/UMEC/VI $(100 \mu \mathrm{g} / 62.5 \mu \mathrm{g} / 25 \mu \mathrm{g})$ with dual combinations of FF/VI $(100 \mu \mathrm{g} / 25 \mu \mathrm{g})$ or UMEC/ VI $(62.5 \mu \mathrm{g} / 25 \mu \mathrm{g})$, administered using the
ELLIPTA inhaler (GlaxoSmithKline plc, Brentford, UK), on the rate of moderate or severe COPD exacerbations. Secondary objectives included changes in symptoms and HRQoL.

\section{Participants}

Eligible patients were $\geq 40$ years old, with symptomatic COPD (COPD Assessment Test [CAT] score $\geq 10$ ) and either a forced expiratory volume in $1 \mathrm{~s}\left(\mathrm{FEV}_{1}\right)<50 \%$, predicted together with a history of $\geq 1$ moderate or severe exacerbation in the previous year, or an $\mathrm{FEV}_{1}$ of $50-80 \%$ predicted with $\geq 2$ moderate exacerbations or $\geq 1$ severe exacerbation in the previous year. All patients were required to provide written informed consent.

\section{Efficacy Outcomes}

The following patient-reported assessments of HRQoL and dyspnea were included in the IMPACT study: St George's Respiratory Questionnaire for COPD patients (SGRQ-C; converted to SGRQ), the Baseline Dyspnea Index (BDI) as the anchor for the Transitional Dyspnea Index (TDI) focal score (BDI/TDI), and the CAT. BDI/TDI data were only collected for a subset of patients at sites in Belgium, Canada, the Czech Republic, Denmark, Germany, The Netherlands, Poland, Spain, the UK, and the USA where approved translations of the questionnaire existed. Patient Global Rating of COPD Severity (PGRS) and Patient Rating of Change in Severity of COPD (PGIC) were also collected. All patient-reported data were collected using electronic data capture.

Change from baseline SGRQ total score at week 52 comparing FF/UMEC/VI with FF/VI was a secondary end point, and the comparison with UMEC/VI was exploratory. SGRQ-C, which contains 40 items grouped into three domains to measure the impact of COPD and its treatment on HRQoL [11], was completed at randomization and at weeks 4,28 , and 52 . The score is calculated to be equivalent to the original SGRQ and ranges from 0 to 100; a decrease in score indicates an improvement in HRQoL 
[12]. A four-unit change is regarded as clinically meaningful [13].

BDI was measured in a subgroup of patients enrolled at sites in North America and Europe at randomization and TDI, measuring the change from baseline, which was assessed at weeks 4, 28 , and 52. BDI/TDI was assessed using a selfadministered computerized questionnaire [14]. The scores in both indices depend on ratings for three different categories: functional impairment, magnitude of task, and magnitude of effort [14]. A TDI focal score of $\geq 1$ unit has been defined as meaningful [15].

The CAT was completed at screening, as an inclusion criterion at randomization, and at weeks 4,28 , and 52 . This short validated questionnaire is used in routine clinical practice to measure the health status of patients with COPD [16, 17]. Higher CAT scores indicate greater disease impact, with improvement shown by a decrease in scores. The meaningful improvement for the CAT is a $\geq 2$-unit decrease from baseline [18].

In addition, an electronic daily diary collected responses on limitation in daily activity, rescue medication use, and nighttime awakenings. Baseline mean rescue medication use was only calculated if patients had recorded their use over $\geq 7$ days between day -13 and day 1 .

Patients completed the PGRS at randomization and at all subsequent visits, including the final visit or at treatment discontinuation. This single global question asked patients to rate their COPD severity using a 4-point scale (mild, moderate, severe, very severe). Patients also completed the PGIC comparing change with the previous visit at all study visits subsequent to randomization. PGIC responses are collected on a 7-point Likert scale (ranging through much better, better, slightly better, no change, slightly worse, worse, and much worse). This measure was included to be used as an anchor to determine meaningful changes from baseline in other study parameters. The response option 'slightly better' was used as the anchor to determine a minimum detectable change.

\section{Statistical Analyses}

All analyses were performed in the intent-totreat (ITT) population, except for the BDI and TDI, which were assessed in a subset of 5058 patients who completed a BDI assessment at baseline (TDI population). Change from baseline in SGRQ total score was analyzed using a mixed-effect model repeat measurement analysis. Least-square (LS) means and LS mean change from baseline for each treatment group with associated standard errors (SE) and 95\% confidence intervals (CI) were calculated. Estimated treatment differences with corresponding SE, 95\% CI, and $p$ values are also provided. Patients were classified as responders or nonresponders for various end points based on predetermined cutoffs that define a meaningful change using a mixed-effect model repeat measurement (MMRM). Patients with missing on-treatment data were imputed as non-responders at all subsequent visits, up to and including week 52; the only exception was for intermittent missingness, where data were recorded as missing. The proportion of responders was analyzed using a generalized linear mixed model with a logit link function. The number and percentage of patients achieving or not achieving a response was calculated as an odds ratio (OR) with corresponding 95\% CI and $p$ value for the pairwise comparisons. Different levels of response were defined for SGRQ total score by directly mapping individual change in SGRQ total score against the patient's PGIC, using the mean change in SGRQ total score for each response to PGIC to provide a more complete picture of effect on HRQoL for each treatment group.

\section{RESULTS}

\section{Study Population}

The ITT population comprised 10,355 patients (FF/UMEC/VI, $n=4151 ; \mathrm{FF} / \mathrm{VI}, n=4134$; and $\mathrm{UMEC} / \mathrm{VI}, \quad n=2070)$. The TDI population included 5058 patients (FF/UMEC/VI, $n=2029$; FF/VI, $n=2014$; and UMEC/VI, $n=1015$ ) who completed a BDI assessment at baseline. 
Table 1 Baseline demographics and patient characteristics in the ITT and TDI populations

\begin{tabular}{|c|c|c|c|c|}
\hline & FF/UMEC/VI & FF/VI & UMEC/VI & Overall \\
\hline ITT population $[2]$ & $(n=4151)$ & $(n=4134)$ & $(n=2070)$ & $(N=10,355)$ \\
\hline Mean age (SD), years & $65.3(8.2)$ & $65.3(8.3)$ & $65.2(8.3)$ & $65.3(8.3)$ \\
\hline Male, $n(\%)$ & $2766(67)$ & $2748(66)$ & $1356(66)$ & $6870(66)$ \\
\hline Former smoker, $n(\%)$ & $2715(65)$ & $2711(66)$ & $1342(65)$ & $6768(65)$ \\
\hline Baseline CAT score & $(n=4076)$ & $(n=4047)$ & $(n=2034)$ & NA \\
\hline Mean (SD) & $18.2(6.98)$ & $18.3(6.99)$ & $18.1(6.88)$ & NA \\
\hline Baseline SGRQ total score & $(n=4108)$ & $(n=4092)$ & $(n=2050)$ & NA \\
\hline Mean (SD) & $50.8(16.8)$ & $50.7(17.0)$ & $50.2(16.7)$ & NA \\
\hline Baseline pre-bronchodilator $\%$ predicted $\mathrm{FEV}_{1}$ & $(n=4144)$ & $(n=4133)$ & $(n=2068)$ & $(n=10,345)$ \\
\hline Mean (SD) & $41.9(14.6)$ & $41.6(14.4)$ & $41.8(14.4)$ & $41.8(14.5)$ \\
\hline Baseline post-bronchodilator $\%$ predicted $\mathrm{FEV}_{1}$ & $(n=4145)$ & $(n=4133)$ & $(n=2069)$ & $(n=10,347)$ \\
\hline Mean (SD) & $45.7(15.0)$ & $45.5(14.8)$ & $45.4(14.7)$ & $45.5(14.8)$ \\
\hline GOLD grade, $n(\%)$ & $(n=4145)$ & $(n=4133)$ & $(n=2069)$ & $(N=10,347)$ \\
\hline 1 (mild; \% predicted $\mathrm{FEV}_{1} \geq 80$ ) & $10(<1)$ & $8(<1)$ & $4(<1)$ & $22(<1)$ \\
\hline $2\left(\right.$ moderate; $\geq 50 \%$ predicted $\left.\mathrm{FEV}_{1}<80\right)$ & $1535(37)$ & $1455(35)$ & $729(35)$ & $3719(36)$ \\
\hline 3 (severe; $\geq 30 \%$ predicted $\mathrm{FEV}_{1}<50$ ) & $1934(47)$ & $2031(49)$ & $1017(49)$ & $4982(48)$ \\
\hline $4\left(\right.$ very severe; $\%$ predicted $\left.\mathrm{FEV}_{1}<30\right)$ & $666(16)$ & $639(15)$ & $319(15)$ & $1624(16)$ \\
\hline Exacerbation history in the previous year, $n(\%)$ & $(n=4151)$ & $(n=4134)$ & $(n=2070)$ & $(N=10,355)$ \\
\hline$\geq 1$ moderate and no severe & $1198(29)$ & $1242(30)$ & $616(30)$ & $3056(30)$ \\
\hline$\geq 2$ moderate or $\geq 1$ severe & $2953(71)$ & $2892(70)$ & $1454(70)$ & $7299(70)$ \\
\hline TDI population* & $(n=2029)$ & $(n=2014)$ & $(n=1015)$ & $(N=5058)$ \\
\hline Mean age (SD), years & $64.6(8.2)$ & $64.8(8.3)$ & $64.5(8.3)$ & $64.7(8.3)$ \\
\hline Male, $n(\%)$ & $1151(57)$ & $1134(56)$ & $571(56)$ & $2856(56)$ \\
\hline Mean BDI (SD) & $5.9(1.9)$ & $5.9(2.0)$ & $5.9(2.0)$ & NA \\
\hline
\end{tabular}

$B D I$ Baseline Dyspnea Index, CAT COPD (chronic obstructive pulmonary disease) Assessment Test, $F E V_{1}$ forced expiratory volume in $1 \mathrm{~s}, F F$ fluticasone furoate, GOLD Global Initiative for Chronic Obstructive Lung Disease, ITT intent to treat, $N A$ not available (not measured at screening), $S D$ standard deviation, $S G R Q$ St George's Respiratory Questionnaire, $T D I$ Transitional Dyspnea Index, UMEC umeclidinium, $V I$ vilanterol

*BDI/TDI data were only collected for a subset of patients at sites in Belgium, Canada, the Czech Republic, Denmark, Germany, The Netherlands, Poland, Spain, the UK, and the USA where approved translations of the questionnaire existed

Baseline demographics (Table 1) and CAT scores were broadly similar between treatment arms in both the ITT and TDI populations. Further discussion of patient demographics in the IMPACT study has been previously published [2]. 


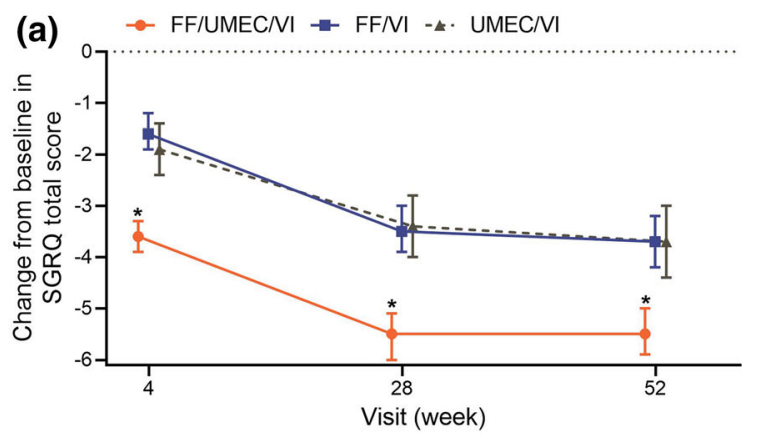

(b)
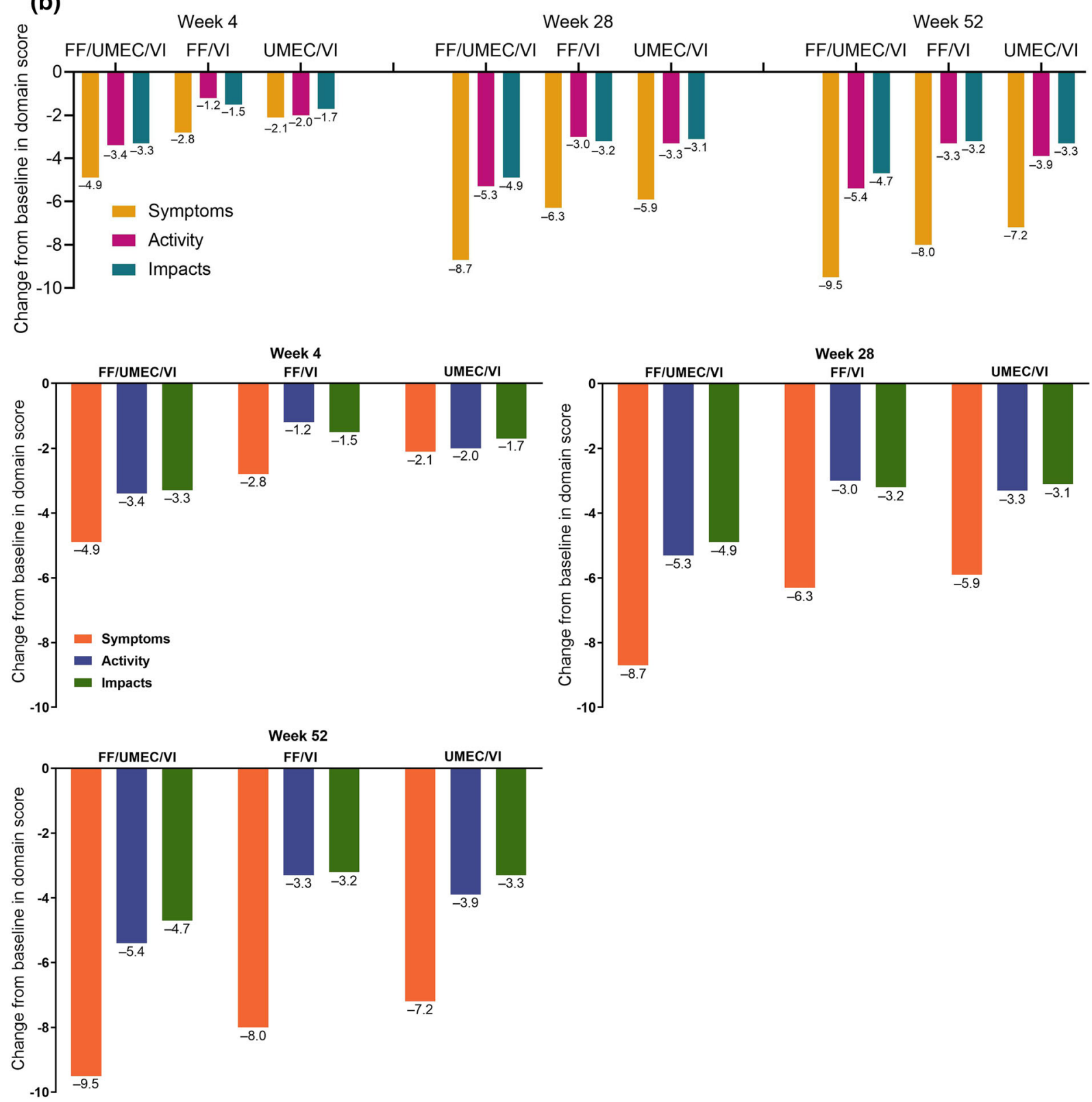
4Fig. 1 a LS mean change (95\% CI) from baseline in SGRQ total score; $\mathbf{b}$ mean change from baseline in SGRQ domain scores over 52 weeks (ITT population). ${ }^{*} p<0.001$ for FF/UMEC/VI compared with FF/VI or UMEC/VI. CI confidence interval, FF fluticasone furoate, $I T T$ intent to treat, $L S$ least squares, $S G R Q$ St George's Respiratory Questionnaire, UMEC umeclidinium, VI vilanterol

\section{SGRQ}

Baseline SGRQ total scores were similar across all three treatment groups (Table 1). Patients receiving $\mathrm{FF} / \mathrm{UMEC} / \mathrm{VI}$ demonstrated a clinically meaningful improvement in the LS mean change from baseline in SGRQ total score at week 52 of -5.5 units (Fig. 1a). As previously reported, improvements in the LS mean change from baseline in SGRQ total score at week 52 for $\mathrm{FF} / \mathrm{VI}$ and UMEC/VI were - 3.7 units for both groups [2]. Statistically significant differences in LS mean change from baseline of SGRQ total score favoring $\mathrm{FF} / \mathrm{UMEC} / \mathrm{VI}$ were observed at week 52 compared with FF/VI ( -1.8 units, 95\% $\mathrm{CI}-2.4$ to $-1.1, p<0.001)$ and UMEC/VI ( -1.8 units, $95 \%$ CI -2.6 to $-1.0, p<0.001)$. Improvements favoring FF/UMEC/VI compared with $\mathrm{FF} / \mathrm{VI}$ or UMEC/VI were observed at all time points (all $p<0.001$, Fig. 1a). This pattern was also apparent for all three SGRQ domain scores, with greater decreases from baseline observed at weeks 4,28 , and 52 in those who received $\mathrm{FF} / \mathrm{UMEC} / \mathrm{VI}$ compared with those who received either FF/VI or UMEC/VI (Fig. 1b).

At week 52, a larger proportion of patients within the FF/UMEC/VI treatment group were SGRQ responders compared with the FF/VI or UMEC/VI groups (Table 2). The odds of being an SGRQ responder versus a non-responder at week 52 were statistically significantly higher for patients who received FF/UMEC/VI compared with FF/VI (OR, 1.41, 95\% CI 1.29-1.55, $p<0.001)$ or UMEC/VI (OR, 1.41, 95\% CI 1.26-1.57, $p<0.001)$.

Mapping SGRQ total score change from baseline across all treatment arms using the global rating of change in COPD severity as a global anchor of change demonstrated that a reduction of three points in SGRQ total score $(n=2213)$ was associated with a response of 'slightly better' on the PGIC, lower than the 4-point change, which is considered to be clinically meaningful. A moderate response was associated with a reduction from baseline (improvement in HRQOL) in SGRQ total score of $\geq 8$ units $(n=2096)$, and a major response with a reduction from baseline of $\geq 14$ units $(n=982)$. Changes from baseline in SGRQ total score for those who reported worsening followed a similar pattern with an increase of $\geq 3$ points for 'slightly worse' $(n=581)$ and $\geq 6$ points for moderate worsening $(n=201)$. Few patients $(n=33)$ reported major worsening with wide variability in change from baseline SGRQ total score.

At week 52, the likelihood of being a major/moderate responder compared with a less than major/moderate responder by SGRQ was higher for patients randomized to receive $\mathrm{FF} /$ UMEC/VI compared with those randomized to receive either FF/VI or UMEC/VI (both $p<0.001$ ). The odds of being a major responder compared with a less than major responder were also higher following treatment with $\mathrm{FF} /$ UMEC/VI compared with either FF/VI or UMEC/VI (both $p<0.001$, Table 2).

\section{CAT}

A CAT score $\geq 10$ was required for enrollment to IMPACT. When measured at baseline, CAT scores were similar across all three treatment groups (Table 1). In the ITT population $(n=10,355)$, a clinically meaningful and statistically significant improvement in LS mean change from baseline in CAT score was observed at all time points for $\mathrm{FF} / \mathrm{UMEC} / \mathrm{VI}$ compared with FF/VI or UMEC/VI, with the exception of the comparison with UMEC/VI at week 28. At week 52, the LS mean change from baseline was -2.0 units for those patients treated with $\mathrm{FF} /$ UMEC/VI, - 1.5 units with FF/VI, and - 1.6 units with UMEC/VI (Fig. 2).

Compared with the other treatment groups, a larger proportion of patients in the FF/UMEC/ VI group were CAT responders versus the FF/VI or UMEC/VI groups (Table 2). The odds of being 
Table 2 Proportion of responders at week 52

\begin{tabular}{|c|c|c|c|}
\hline & FF/UMEC/VI & FF/VI & UMEC/VI \\
\hline SGRQ* & $(n=4108)$ & $(n=4092)$ & $(n=2050)$ \\
\hline Responder, $n(\%)$ & $1723(42)$ & $1390(34)$ & $696(34)$ \\
\hline Non-responder, $n(\%)$ & $2385(58)$ & $2702(66)$ & $1354(66)$ \\
\hline \multicolumn{4}{|l|}{ FF/UMEC/VI vs. column } \\
\hline OR & - & 1.41 & 1.41 \\
\hline $95 \% \mathrm{CI}$ & - & $1.29-1.55$ & $1.26-1.57$ \\
\hline$p$ value & - & $<0.001$ & $<0.001$ \\
\hline Major/moderate responder, $n(\%)$ & $1298(32)$ & $1034(25)$ & $495(24)$ \\
\hline Major responder, $n(\%)$ & $749(18)$ & $609(15)$ & $291(14)$ \\
\hline Moderate responder, $n(\%)$ & $549(13)$ & $425(10)$ & $204(10)$ \\
\hline Less than moderate responder, $n(\%)$ & $2810(68)$ & $3058(75)$ & $1555(76)$ \\
\hline \multicolumn{4}{|c|}{ FF/UMEC/VI: major/moderate responder vs. less than major/moderate responder vs. column } \\
\hline OR & - & 1.38 & 1.45 \\
\hline $95 \% \mathrm{CI}$ & - & $1.25-1.52$ & $1.29-1.64$ \\
\hline$p$ value & - & $<0.001$ & $<0.001$ \\
\hline \multicolumn{4}{|c|}{ FF/UMEC/VI: major responder vs. less than major responder vs. column } \\
\hline OR & - & 1.29 & 1.35 \\
\hline $95 \% \mathrm{CI}$ & - & $1.15-1.45$ & $1.16-1.56$ \\
\hline$p$ value & - & $<0.001$ & $<0.001$ \\
\hline CAT score ${ }^{\dagger}$ & $(n=4076)$ & $(n=4047)$ & $(n=2034)$ \\
\hline Responder, $n(\%)$ & $1698(42)$ & $1491(37)$ & $730(36)$ \\
\hline Non-responder, $n(\%)$ & $2378(58)$ & $2556(63)$ & $1304(64)$ \\
\hline \multicolumn{4}{|l|}{ FF/UMEC/VI vs. column } \\
\hline OR & - & 1.24 & 1.28 \\
\hline $95 \% \mathrm{CI}$ & - & $1.14-1.36$ & $1.15-1.43$ \\
\hline$p$ value & - & $<0.001$ & $<0.001$ \\
\hline TDI focal score* & $(n=2029)$ & $(n=2014)$ & $(n=1015)$ \\
\hline Responder, $n$ (\%) & $730(36)$ & $591(29)$ & $302(30)$ \\
\hline Non-responder, $n(\%)$ & $1299(64)$ & $1423(71)$ & $713(70)$ \\
\hline \multicolumn{4}{|l|}{ FF/UMEC/VI vs. column } \\
\hline OR & - & 1.36 & 1.33 \\
\hline $95 \% \mathrm{CI}$ & - & $1.19-1.55$ & $1.13-1.57$ \\
\hline$p$ value & - & $<0.001$ & $<0.001$ \\
\hline
\end{tabular}

CAT COPD (chronic obstructive pulmonary disease) Assessment Test, $C I$ confidence interval, FF fluticasone furoate, $I T T$ intent to treat, $O R$ odds ratio, SGRQ St George's Respiratory Questionnaire, TDI Transitional Dyspnea Index, UMEC umeclidinium, VI vilanterol

${ }^{*}$ ITT population with analyzable data at week 52; major response defined as an SGRQ total score $\geq 14$-unit decrease below baseline; moderate response defined as $<14$-unit, but $\geq 8$-unit decrease below baseline; less than moderate response defined as $<8$-unit decrease below baseline or a missing SGRQ total score with no subsequent on-treatment scores

† ITT population with analyzable data at week 52; response defined as a CAT score decrease $\geq 2$ units below baseline; non-response defined as $<2$-unit decrease below baseline

$¥$ TDI population with analyzable data at week 52 ; response defined as a TDI focal score of $\geq 1$ unit; non-response defined as TDI focal score of $<1$ unit 


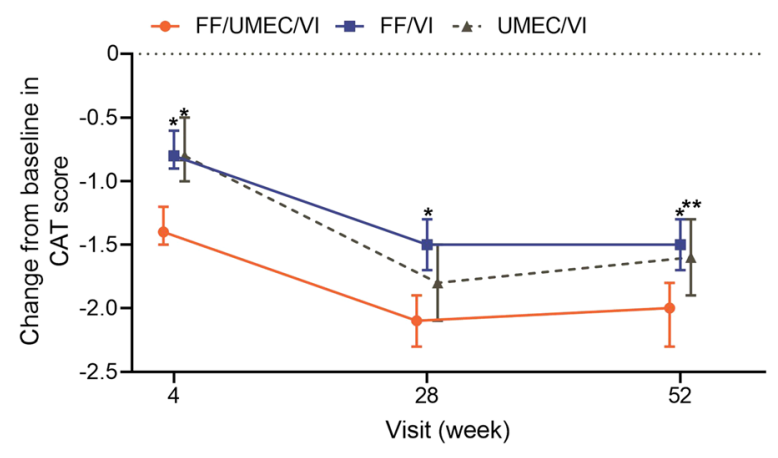

Fig. 2 LS mean change (95\% CI) from baseline in CAT score over 52 weeks (ITT population). ${ }^{*} p<0.001$ for $\mathrm{FF} /$ UMEC/VI compared with FF/VI or UMEC/VI; ${ }^{* *} p=0.021$ for FF/UMEC/VI compared with UMEC/ VI. CAT COPD (chronic obstructive pulmonary disease) Assessment Test, $C I$ confidence interval, $F F$ fluticasone furoate, ITT intent to treat, $L S$ least squares, $U M E C$ umeclidinium, $V I$ vilanterol

a CAT responder versus a non-responder at week 52 were statistically significantly higher for FF/UMEC/VI versus FF/VI (OR, 1.24, 95\% CI $1.14-1.36, p<0.001)$ or UMEC/VI (OR, 1.28, $95 \%$ CI $1.15-1.43, p<0.001)$. The odds of being a CAT responder were also statistically significantly higher at weeks 4 and 28 for the comparison of FF/UMEC/VI with FF/VI (OR, 1.27 and 1.30, respectively; both $p<0.001$ ) or with UMEC/VI (OR, 1.30 and 1.32, respectively; both $p<0.001)$.

\section{TDI Focal Score}

In the TDI subset of patients $(n=5058)$, identical BDI scores were observed across all three treatment groups (Table 1). At week 52, the LS mean TDI focal score in each of the FF/UMEC/ $\mathrm{VI}, \mathrm{FF} / \mathrm{VI}$, and UMEC/VI treatment groups was $0.98,0.71$, and 0.89 points, respectively. Patients in the FF/UMEC/VI group demonstrated a statistically significant improvement in LS mean TDI focal score of 0.27 points compared with FF/VI $(p=0.020)$ at week 52 (Fig. 3); statistically significant improvements in LS mean TDI focal score were also observed at weeks 4 (0.47 points, $p<0.001)$ and $28(0.29$ points, $p=0.006$ ). In contrast, although a statistically significant improvement in LS mean

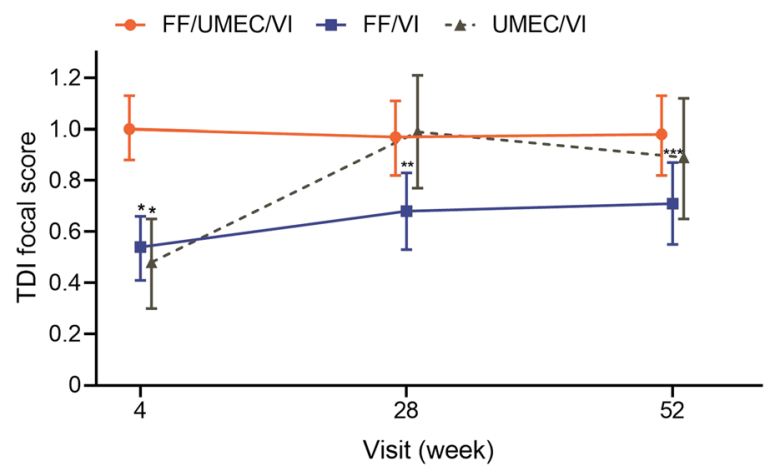

Fig. 3 LS mean (95\% CI) TDI focal score over 52 weeks (TDI population). ${ }^{*} p<0.001$ for FF/UMEC/VI compared with $\mathrm{FF} / \mathrm{VI}$ or $\mathrm{UMEC} / \mathrm{VI} ;{ }^{* *} p=0.006$ for $\mathrm{FF} /$ $\mathrm{UMEC} / \mathrm{VI}$ compared with $\mathrm{FF} / \mathrm{VI} ;{ }^{* * *} p=0.020$ for $\mathrm{FF} /$ UMEC/VI compared with FF/VI. CI confidence interval, $F F$ fluticasone furoate, $L S$ least squares, TDI Transitional Dyspnea Index, $U M E C$ umeclidinium, $V I$ vilanterol

TDI focal score at week 4 (0.53 points, $p<0.001$ ) was observed for FF/UMEC/VI versus UMEC/VI, the difference was not statistically significant at week $28(-0.02$ points, $p=0.872)$ or week 52 (0.09 points, $p=0.522)$.

At week 52, a larger proportion of patients were TDI responders in the FF/UMEC/VI group compared with the FF/VI or UMEC/VI groups (Table 2). Statistically significantly higher odds of being a TDI responder were observed at all time points (weeks 4, 28, and 52, respectively) for $\mathrm{FF} / \mathrm{UMEC} / \mathrm{VI}$ versus $\mathrm{FF} / \mathrm{VI}(\mathrm{OR}, 1.46,1.36$, and 1.36 , all $p<0.001)$ or UMEC/VI (OR, 1.41 $[p \leq 0.001], \quad 1.20 \quad[p \leq 0.027], \quad$ and 1.33 $[p<0.001])$.

\section{Rescue Use and Nighttime Awakenings}

Baseline mean rescue medication use per day was similar across all treatment groups. Although all three treatment groups had a slight increase in rescue medication use over the 52-week treatment period, as measured by LS mean change from baseline, statistically significant differences were observed at each 4-week time period in favor of FF/UMEC/VI compared with FF/VI or UMEC/VI (Fig. 4a). Over weeks 49-52, the LS mean change from baseline in the percentage of rescue medication-free days was smaller with FF/UMEC/VI (-1.9\%) compared 
with $\mathrm{FF} / \mathrm{VI}(-7.1 \%$, treatment difference $5.2 \%$, 95\% CI $3.5-6.9, p<0.001)$ or UMEC/VI (-6.3\%, treatment difference $4.4 \%$, 95\% CI 2.3-6.5, $p<0.001$, Fig. 4b).

At baseline, a similar mean ( \pm standard deviation) number of nighttime awakenings was reported by patients in all treatment groups (0.69 [0.97]; 0.70 [0.98]; 0.69 [0.96] for $\mathrm{FF} /$ UMEC/VI, FF/VI and UMEC/VI, respectively). FF/UMEC/VI demonstrated a statistically significant reduction in the LS mean change from baseline in the mean number of nighttime awakenings per night over weeks 49-52 compared with FF/VI (treatment difference -0.05 awakenings, $p=0.005$ ) or UMEC/VI (treatment difference -0.10 awakenings, $p<0.001$ ). Additionally, with the exceptions of weeks 1-4 $(p=0.070)$ and weeks $33-36(p=0.056)$, statistically significant reductions in the LS mean change from baseline in the mean number of nighttime awakenings per night were observed at each aggregated 4-week time period for $\mathrm{FF} /$ UMEC/VI compared with FF/VI ( $p \leq 0.021)$. However, statistically significant reductions in the LS mean change from baseline in the mean number of nighttime awakenings per night were observed over every 4 -week time period (all $p<0.001$ ) for FF/UMEC/VI compared with UMEC/VI (Fig. 4c).

\section{Activity}

The LS mean change from baseline in the percentage of days symptoms stopped usual activities was statistically significantly smaller for FF/ UMEC/VI (0.6\%) over weeks 49-52 compared with $\mathrm{FF} / \mathrm{VI}(2.7 \%$, treatment difference $-2.1 \%$, $95 \% \mathrm{CI}-3.5$ to $-0.7, p=0.003)$ or $\mathrm{UMEC} / \mathrm{VI}$ (2.5\%, treatment difference $-1.9 \%, 95 \% \mathrm{CI}$ -3.7 to $-0.2, p=0.026$, Table 3 ). At the end of treatment, patients receiving FF/UMEC/VI also had statistically significantly higher odds of being in a better response category versus a worse category for change in activity limitation compared with the previous visit than patients treated with FF/VI ( $p=0.003)$; the difference for UMEC/VI did not reach statistical significance $(p=0.283$, Table 3$)$.
Fig. 4 LS mean change ( $95 \% \mathrm{CI}$ ) from baseline in a use of rescue medication; $\mathbf{b}$ percentage of rescue medication-free days over 52 weeks; c number of nighttime awakenings per week (ITT population). ${ }^{*} p<0.001$ for $\mathrm{FF} / \mathrm{UMEC} / \mathrm{VI}$ compared with FF/VI or UMEC/VI.; ${ }^{* *} p \leq 0.021$ for FF/ UMEC/VI compared with FF/VI. Note: a negative LS mean change from baseline indicates an increase in use of rescue medication. $C I$ confidence interval, $F F$ fluticasone furoate, ITT intent to treat, $L S$ least squares, UMEC umeclidinium, $V I$ vilanterol

\section{DISCUSSION}

The IMPACT study demonstrated a lower rate of moderate or severe COPD exacerbations and better lung function and HRQoL with $\mathrm{FF} /$ UMEC/VI compared with FF/VI or UMEC/VI dual therapy in patients with symptomatic COPD and a history of exacerbations at baseline [2]. Here, we report further detail on the HRQoL results and change in dyspnea observed in the IMPACT trial. The inclusion of valid and responsive measures reporting the patient perspective of treatment allows a more complete description of the effects of FF/UMEC/VI compared with the component dual therapies of FF/ VI or UMEC/VI. The pre-specified analyses of PROs from the IMPACT study presented here expand the primary findings of the study [2] and further demonstrate that FF/UMEC/VI improved patient perceptions of both symptom severity and health status compared with FF/VI or UMEC/VI. The use of global anchor questions to assess improvements in HRQoL has demonstrated that FF/UMEC/VI provides benefits over FF/VI and UMEC/VI beyond a minimal level of improvement.

These results also demonstrate that the effects of dual bronchodilation on lung function, whether combined with ICS in a triple therapy or not [2], are reflected in the patient perception of dyspnea, measured using the TDI focal score. Improvements in the TDI focal score with FF/UMEC/VI are apparent at 4 weeks postrandomization and are sustained for 52 weeks. An improvement in perception of dyspnea was observed with UMEC/VI at weeks 28 and 52, which is similar to that observed with $\mathrm{FF} /$ UMEC/VI, a consequence of patients receiving 


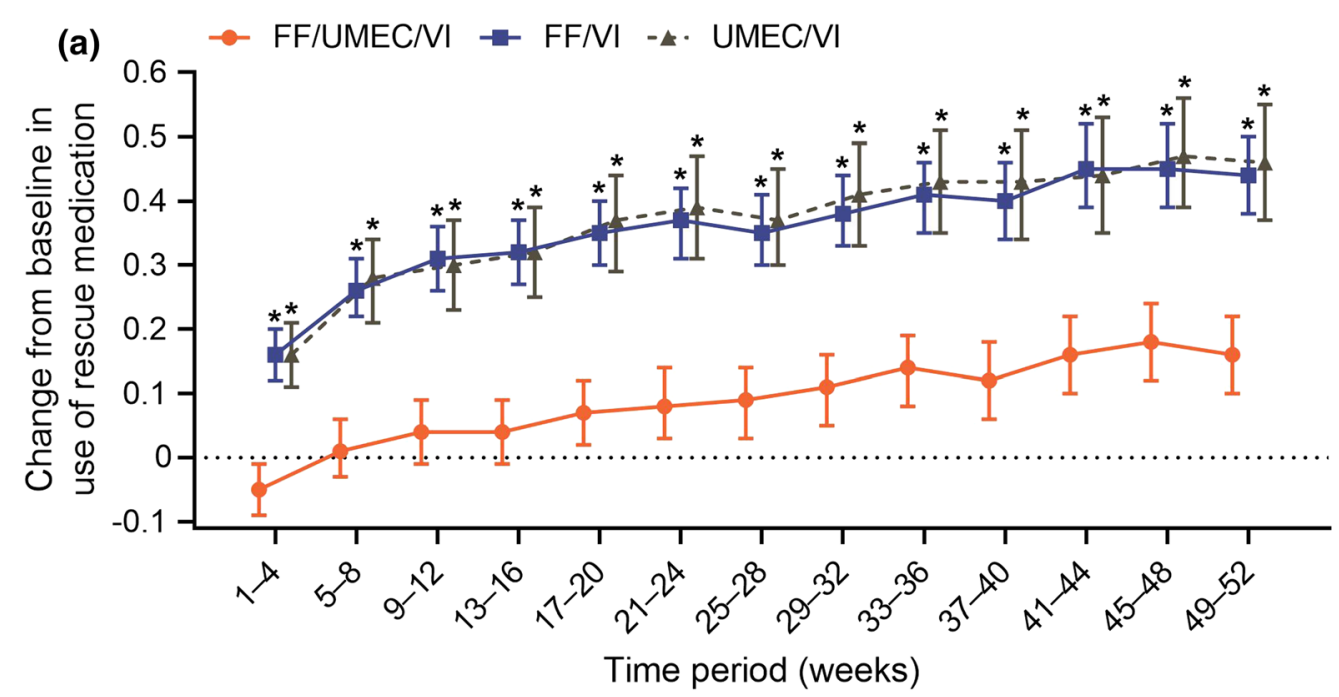

(b)
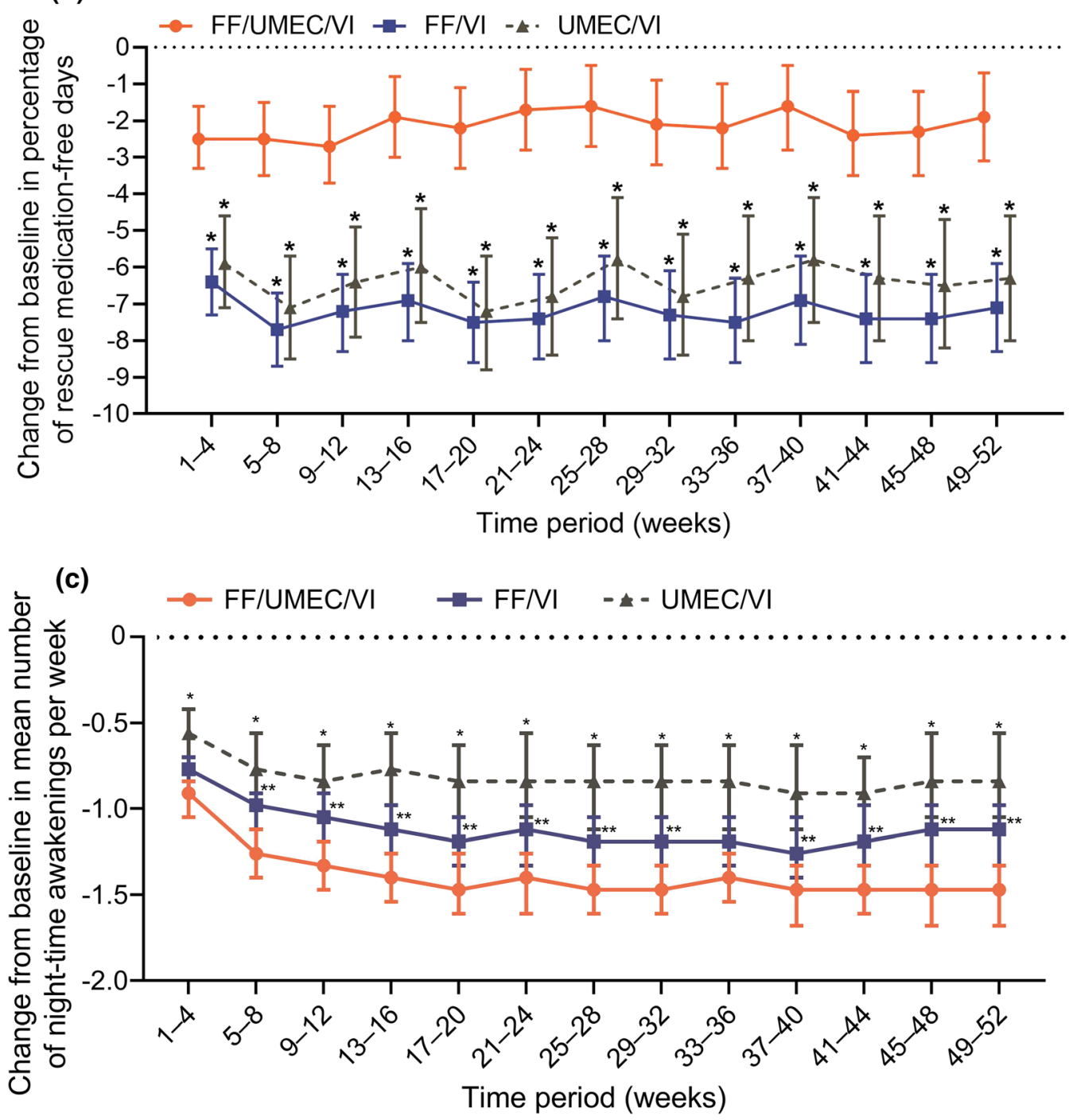
dual bronchodilation. Treatment with FF/VI showed less improvement in dyspnea at all time points.

Additionally, the reduced use of rescue medication in the FF/UMEC/VI arm compared with FF/VI or UMEC/VI can be regarded as an indicator of benefits in terms of symptoms. There was also a reduction in nighttime awakenings due to COPD symptoms in the $\mathrm{FF} /$ UMEC/VI arm compared with either dual therapy. Previous studies have noted an association among nighttime awakenings, decreased health status, and an increase in the need for rescue medication [19-21]. Reducing the frequency of these events may also positively influence health status [20].

Rapid and sustained improvements in HRQoL, measured by both the SGRQ total score and the CAT, were seen by week 4 , maximal at week 28, and maintained to week 52 . The improvements in SGRQ occurred earlier in the IMPACT study than those observed in either the FLAME trial [22] or the TRILOGY trial [23] where improvements in SGRQ total score were not observed until week 12 . These results are also reflected in the improvement in lung function observed with triple therapy in the IMPACT study [2]. Our work further demonstrates the comparability of the SGRQ and CAT and provides further evidence to support the usefulness of the CAT in routine clinical practice as a short and easily applied measure of health status.

The timing of perceived changes in HRQoL can be indicative of improvements in symptoms, with early changes in measures such as the SGRQ and CAT driven by reductions in symptoms. The rapid yet sustained improvement in HRQoL potentially reflects a combination of the treatment effects of FF/UMEC/VI, with early improvement more likely to occur because of symptomatic relief, as demonstrated by the proportionally greater early improvement in the SGRQ symptoms domain. The comparison between groups for the domain scores is more nuanced than the results for the SGRQ total score. In earlier measurements at week 4 , change in the activity domain score was minimal in the FF/VI group, although this was not seen at later time points and was likely related to the more immediate effects of dual bronchodilation in the FF/UMEC/VI and UMEC/VI arms. Later sustained effects on HRQoL were apparent across all treatment groups with a statistically superior improvement in the FF/UMEC/VI treatment group compared with both dual treatment groups.

In the Lung Function and Quality of Life Assessment in COPD with Closed Triple Therapy (FULFIL) study (NCT02345161), comparing FF/UMEC/VI with budesonide/formoterol, both treatments improved HRQoL $[1,6]$. The same trend was observed in this study with all treatment groups showing improvements from baseline. When comparing changes in PRO scores between treatment groups, it is important to consider the change from baseline within the groups and whether it is meaningful to patients to provide context. In a study comparing only active treatments, responder analyses provide the most meaningful comparison; achieving a between-groups difference greater than the accepted threshold for a meaningful change is not to be expected given that all patient groups are expected to show improvements over the course of the study. Hence, the findings from this and other studies that have demonstrated a greater proportion of SGRQ responders among those patients who received triple therapy regimens compared with monotherapy or dual therapy are encouraging $[23,24]$.

Strengths of this study include the use of an electronic diary for reliable recording of HRQoL. Potential limitations include the study of a population with predominantly moderate-tovery severe COPD. Thus, the effect of FF/UMEC/ VI versus $\mathrm{FF} / \mathrm{VI}$ or UMEC/VI on HRQoL in patients with mild COPD was not examined.

These results show that therapy with oncedaily FF/UMEC/VI single-inhaler triple therapy improves patient symptoms and HRQoL compared with dual treatment with FF/VI or UMEC/ VI in patients with symptomatic COPD and at risk of exacerbations. These findings are associated with the benefits on exacerbations, hospitalization, and lung function reported previously [2]. Moreover, despite the significant benefits of treatment with a long-acting muscarinic antagonist on symptomology, compared 
Table 3 Effects of symptoms of COPD on patients' activities

\begin{tabular}{|c|c|c|c|}
\hline & $\begin{array}{l}\text { FF/UMEC/ } \\
\text { VI }\end{array}$ & FF/VI & UMEC/VI \\
\hline Percentage of days symptoms stopped usual activities (weeks 49-52)* & $(n=3322)$ & $(n=3002)$ & $(n=1462)$ \\
\hline LS mean $(\mathrm{SE})$ & $26.4(0.49)$ & $28.5(0.51)$ & $28.3(0.72)$ \\
\hline $95 \% \mathrm{CI}$ & $25.4-27.4$ & $27.5-29.5$ & $26.9-29.8$ \\
\hline LS mean change from baseline (SE) & $0.6(0.49)$ & $2.7(0.51)$ & $2.5(0.72)$ \\
\hline $95 \%$ CI & -0.4 to 1.5 & $1.7-3.7$ & $1.1-3.9$ \\
\hline \multicolumn{4}{|l|}{ FF/UMEC/VI vs. column } \\
\hline Difference (SE) & - & $-2.1(0.71)$ & $-1.9(0.88)$ \\
\hline $95 \% \mathrm{CI}$ & - & $\begin{array}{c}-3.5 \text { to } \\
-0.7\end{array}$ & $\begin{array}{c}-3.7 \text { to } \\
-0.2\end{array}$ \\
\hline$p$ value & - & 0.003 & 0.026 \\
\hline $\begin{array}{l}\text { Global impression of change in activity limitation at the end of treatment, } \\
n(\%)^{\dagger}\end{array}$ & $(n=3325)$ & $(n=3033)$ & $(n=1470)$ \\
\hline Much better & $233(7)$ & $207(7)$ & $100(7)$ \\
\hline Better & $767(23)$ & $613(20)$ & $336(23)$ \\
\hline Slightly better & $858(26)$ & $789(26)$ & $370(25)$ \\
\hline No change & $1154(35)$ & $1102(36)$ & $507(34)$ \\
\hline Slightly worse & $217(7)$ & $243(8)$ & $119(8)$ \\
\hline Worse & $81(2)$ & $69(2)$ & $30(2)$ \\
\hline Much worse & $15(<1)$ & $10(<1)$ & $8(<1)$ \\
\hline \multicolumn{4}{|l|}{ Comparison to $\mathrm{FF} / \mathrm{UMEC} / \mathrm{VI}^{*}$} \\
\hline Ordered OR & - & 1.15 & 1.06 \\
\hline $95 \% \mathrm{CI}$ & - & $1.05-1.25$ & $0.95-1.19$ \\
\hline$p$ value & - & 0.003 & 0.283 \\
\hline
\end{tabular}

$C I$ confidence interval, $C O P D$ chronic obstructive pulmonary disease, $F F$ fluticasone furoate, $I T T$ intent to treat, $L S$ least squares, $O R$ odds ratio, $S E$ standard error, $U M E C$ umeclidinium, $V I$ vilanterol

*ITT population with analyzable data between weeks 49-52

$\dagger$ ITT population with analyzable data at week 52

* Odds of being in a better response category versus a worse category for change in activity limitation compared with previous visit

with the lesser benefits of ICS on exacerbation reduction, in this study and patient population it would appear that the addition of FF or UMEC to VI has a similar magnitude of impact. The inclusion of pre-specified measures providing the patient perspective gives additional information to the clinician to inform treatment choice and ongoing monitoring of therapy. Therapy with once-daily FF/UMEC/VI improves the symptoms and HRQoL of patients with COPD compared with FF/VI or UMEC/VI; these findings are likely a consequence of the 
previously reported benefits on exacerbations and lung function.

\section{ACKNOWLEDGEMENTS}

The authors thank the patients and physicians who participated in the IMPACT trial, without whom this study would not have been possible. Trademarks are the property of their respective owners. Dave Singh is supported by the National Institute for Health Research (NIHR) Manchester Biomedical Research Centre (BRC).

Funding. This study was funded by GlaxoSmithKline plc (CTT116855; clinicaltrials.gov ID: NCT02164513). GlaxoSmithKline plc also funded the Rapid Service and Open Access Fee for this manuscript.

Medical Writing Assistance. Editorial support (in the form of writing assistance, collating author comments, assembling tables/figures, grammatical editing, fact checking, and referencing) was provided by Sarah Birch, PhD, Contract Senior Medical Writer, and Molly Macpherson, BSc, Senior Medical Writer, of Gardiner-Caldwell Communications (Macclesfield, UK), and was funded by GlaxoSmithKline plc.

Authorship. All named authors meet the International Committee of Medical Journal Editors (ICMJE) criteria for authorship for this article, take responsibility for the integrity of the work as a whole, and have given their approval for this version to be published.

Authorship contributions. Maggie Tabberer, Steven Pascoe, and David A. Lipson: study design, data analysis, and interpretation. Gerard J. Criner and Mark T. Dransfield: data acquisition and interpretation. C. Elaine Jones, Sally Kilbride, David M.G. Halpin, David A. Lomas, Dave Singh, Robert A. Wise, Peter Lange, MeiLan K. Han, Fernando J. Martinez, and Morrys C. Kaisermann: data analysis and interpretation.
Disclosures. Maggie Tabberer, C. Elaine Jones, Sally Kilbride, Morrys C. Kaisermann, and David A. Lipson are employees of, and hold stocks/shares in, GlaxoSmithKline plc. David M.G. Halpin has received personal fees from AstraZeneca, Boehringer Ingelheim, Chiesi, GlaxoSmithKline plc, Novartis, Pfizer and Sanofi, and non-financial support from Boehringer Ingelheim and Novartis. David A. Lomas has received grant income, honoraria, and consultancy fees from GlaxoSmithKline plc, and personal fees from Grifols, and chaired the GSK Respiratory Therapy Area Board 2012-2015. Steven Pascoe was an employee of GlaxoSmithKline plc at the time of the study, holds stocks in GlaxoSmithKline plc, and is currently an employee of CSL Behring. Dave Singh has received personal fees from GlaxoSmithKline plc, AstraZeneca, Boehringer Ingelheim, Chiesi, Cipla, Genentech, Glenmark, Menarini, Mundipharma, Novartis, Peptinnovate, Pfizer, Pulmatrix, Theravance and Verona, and grant support from AstraZeneca, Boehringer Ingelheim, Chiesi, Glenmark, Menarini, Mundipharma, Novartis, Pfizer, Pulmatrix, Theravance and Verona. Robert A. Wise has received received personal fees from AstraZeneca/MedImmune, Boehringer Ingelheim, ContraFect, Pulmonx, Roche, Spiration, Sunovion, Merck, Circassia, Pneuma, Verona, Bonti, Denali, Aradigm, Mylan/Theravance, Propeller Health, AbbVie and GSK, and grant support from AstraZeneca/MedImmune, Boehringer Ingelheim, Pearl Therapeutics, GSK, and SanofiAventis. Gerard Criner has received personal fees from Almirall, Amgen, AstraZeneca, Boehringer Ingelheim, Broncus Medical, Chiesi, CSA Medical, Eolo, Gala Therapeutics, GSK, Helios Medical, Medtronic, Merck, Mereo BioPharma, NGM Pharmaceuticals, Novartis, Nuvaira, Olympus, Philips Respironics, Pulmonx, Respivant Sciences, The Implementation Group, and Verona. He also has ownership interest in HGE Technologies. Peter Lange has received personal fees from GlaxoSmithKline plc, AstraZeneca, and Boehringer Ingelheim, and grant support from Boehringer Ingelheim and GlaxoSmithKline plc. Mark T. Dransfield has received personal fees from AstraZeneca, Boehringer Ingelheim, PneumRx/BTG, Quark 
Pharmaceuticals and GlaxoSmithKline plc, grant support from the American Lung Association, Department of Defense, Department of Veterans Affairs, and NIH, and contracted clinical trial support from Boehringer Ingelheim, Novartis, AstraZeneca, Yungjin, PneumRx/BTG, Pulmonx, Boston Scientific, Gala, Nuvaira, and GlaxoSmithKline plc. Fernando J. Martinez has received personal fees and non-financial support from the American College of Chest Physicians, AstraZeneca, Boehringer Ingelheim, Continuing Education, ConCert, Genentech, GlaxoSmithKline plc, Inova Fairfax Health System, Miller Communications, National Society for Continuing Education, Novartis, Pearl Pharmaceuticals, PeerView Communications, Prime Communications, Puerto Rico Respiratory Society, Chiesi, Roche, Sunovion, Theravance, Potomac, University of Alabama Birmingham, Physicians Education Resource, Canadian Respiratory Network and Teva, nonfinancial support from ProterrixBio, Gilead, Nitto and Zambon, and personal fees from Columbia University, Integritas, MD Magazine, Methodist Hospital Brooklyn, New York University, Unity, UpToDate, WedMD/MedScape, Western Connecticut Health Network, Academic CME, Patara, PlatformIQ, American Thoracic Society, Rockpointe and France Foundation, grant support from NIH, Rare Disease Health Communications and ProMedior, and is a member of steering committees for Afferent/ Merck, Biogen, Veracyte, Prometic, Bayer and Bridge Biotherapeutics.

Prior Presentation. These data were presented at the ERS International Congress 2018 (Tabberer M, et al. European Respiratory Journal 2018 52: OA1658. Tabberer M, et al. European Respiratory Journal 2018 52: PA1996) and at the American Thoracic Society 2019 International Conference (Kaisermann M, et al, American Journal of Respiratory and Critical Care Medicine 2019;199:A3347).

\section{Compliance with Ethics Guideli-} nes. IMPACT was conducted in accordance with Good Clinical Practice guidelines and the provisions of the Declaration of Helsinki and received approval from local institutional review boards or independent ethics committees. Informed consent was obtained from all participants.

Data Availability. Anonymised individual participant data and study documents can be requested for further research from www.clinicalstudydatarequest.com.

Open Access. This article is licensed under a Creative Commons Attribution-NonCommercial 4.0 International License, which permits any non-commercial use, sharing, adaptation, distribution and reproduction in any medium or format, as long as you give appropriate credit to the original author(s) and the source, provide a link to the Creative Commons licence, and indicate if changes were made. The images or other third party material in this article are included in the article's Creative Commons licence, unless indicated otherwise in a credit line to the material. If material is not included in the article's Creative Commons licence and your intended use is not permitted by statutory regulation or exceeds the permitted use, you will need to obtain permission directly from the copyright holder. To view a copy of this licence, visit http://creativecommons.org/licenses/by$\mathrm{nc} / 4.0 /$.

\section{REFERENCES}

1. Lipson DA, Barnacle H, Birk R, Brealey N, Locantore $\mathrm{N}$, Lomas DA, et al. FULFIL trial: once-daily triple therapy for patients with chronic obstructive pulmonary disease. Am J Respir Crit Care Med. 2017;196(4):438-46.

2. Lipson DA, Barnhart F, Brealey N, Brooks J, Criner GJ, Day NC, et al. Once-daily single-inhaler triple versus dual therapy in patients with COPD. N Engl J Med. 2018;378(18):1671-80.

3. Mosenifar Z, Oppenheimer JJ. Chronic Obstructive Pulmonary Disease (COPD): Medscape. 2019. https://emedicine.medscape.com/article/297664print.

4. Ding B, Small M, Bergstrom G, Holmgren U. COPD symptom burden: impact on health care resource utilization, and work and activity impairment. Int J Chron Obstruct Pulmon Dis. 2017;12:677-89. 
5. Tselebis A, Pachi A, Ilias I, Kosmas E, Bratis D, Moussas G, et al. Strategies to improve anxiety and depression in patients with COPD: a mental health perspective. Neuropsychiatr Dis Treat. 2016;12: 297-32828.

6. Tabberer M, Lomas DA, Birk R, Brealey N, Zhu CQ, Pascoe $S$, et al. Once-daily triple therapy in patients with COPD: patient-reported smptoms and quality of life. Adv Ther. 2018;35(1):56-71.

7. Mackay AJ, Kostikas K, Murray L, Martinez FJ, Miravitlles M, Donaldson G, et al. Patient-reported outcomes for the detection, quantification, and evaluation of chronic obstructive pulmonary disease exacerbations. Am J Respir Crit Care Med. 2018;198(6):730-8.

8. Jones P, Miravitlles M, van der Molen T, Kulich K. Beyond FEV(1) in COPD: a review of patient-reported outcomes and their measurement. Int J Chron Obstruct Pulmon Dis. 2012;7:697-709.

9. Ousmen A, Touraine C, Deliu N, Cottone F, Bonnetain F, Efficace F, et al. Distribution- and anchorbased methods to determine the minimally important difference on patient-reported outcome questionnaires in oncology: a structured review. Health Qual Life Outcomes. 2018;16(1):228.

10. Pascoe SJ, Lipson DA, Locantore N, Barnacle $H$, Brealey N, Mohindra R, et al. A phase III randomised controlled trial of single-dose triple therapy in COPD: the IMPACT protocol. Eur Respir J. 2016;48(2):320-30.

11. Meguro M, Barley EA, Spencer S, Jones PW. Development and validation of an improved, COPDspecific version of the St. George Respiratory Questionnaire. Chest. 2007;132(2):456-63.

12. Jones PW, Rennard S, Tabberer M, Riley JH, Vahdati-Bolouri M, Barnes NC. Interpreting patient-reported outcomes from clinical trials in COPD: a discussion. Int $\mathrm{J}$ Chron Obstruct Pulmon Dis. 2016;11:3069-78.

13. Jones PW, Beeh KM, Chapman KR, Decramer M, Mahler DA, Wedzicha JA. Minimal clinically important differences in pharmacological trials. Am J Respir Crit Care Med. 2014;189(3):250-5.

14. Mahler DA, Ward J, Fierro-Carrion G, Waterman LA, Lentine TF, Mejia-Alfaro R, et al. Development of self-administered versions of modified baseline and transition dyspnea indexes in COPD. COPD. 2004;1(2):165-72.
15. Witek TJ Jr, Mahler DA. Minimal important difference of the transition dyspnoea index in a multinational clinical trial. Eur Respir J. 2003;21(2): 267-72.

16. Jones P, Harding G, Wiklund I, Berry P, Leidy N. Improving the process and outcome of care in COPD: development of a standardised assessment tool. Prim Care Respir J. 2009;18(3):208-15.

17. Jones PW, Harding G, Berry P, Wiklund I, Chen WH, Kline LN. Development and first validation of the COPD assessment test. Eur Respir J. 2009;34(3): 648-54.

18. Kon SSC, Canavan JL, Jones SE, Nolan CM, Clark $\mathrm{AL}$, Dickson MJ, et al. Minimum clinically important difference for the COPD assessment test: a prospective analysis. Lancet Resp Med. 2014;2(3): 195-203.

19. Calverley PM, Brezinova V, Douglas NJ, Catterall JR, Flenley DC. The effect of oxygenation on sleep quality in chronic bronchitis and emphysema. Am Rev Respir Dis. 1982;126(2):206-10.

20. Calverley PM, Rennard SI, Clerisme-Beaty E, Metzdorf N, Zubek VB, ZuWallack R. Effect of tiotropium on night-time awakening and daily rescue medication use in patients with COPD. Respir Res. 2016;17:27.

21. McNicholas WT, Verbraecken J, Marin JM. Sleep disorders in COPD: the forgotten dimension. Eur Respir Rev. 2013;22(129):365-75.

22. Wedzicha JA, Banerji D, Chapman KR, Vestbo J, Roche N, Ayers RT, et al. Indacaterol-glycopyrronium versus salmeterol-fluticasone for COPD. N Engl J Med. 2016;374(23):2222-34.

23. Singh D, Papi A, Corradi M, Pavlišová I, Montagna I, Francisco C, et al. Single inhaler triple therapy versus inhaled corticosteroid plus long-acting $\beta 2$ agonist therapy for chronic obstructive pulmonary disease (TRILOGY): a double-blind, parallel group, randomised controlled trial. Lancet. 2016;388(10048):963-73.

24. Vestbo J, Papi A, Corradi M, Blazhko V, Montagna I, Francisco C, et al. Single inhaler extrafine triple therapy versus long-acting muscarinic antagonist therapy for chronic obstructive pulmonary disease (TRINITY): a double-blind, parallel group, randomised controlled trial. Lancet. 2017;389(10082): 1919-29. 